\title{
Critical Infrastructure in the Face of a Predatory Future: Preparing for Untoward Surprise
}

\section{Todd R. LaPorte}

Department of Political Science, University of California, Berkeley, CA 94720-1950, USA. E-mail: tlaporte@ socrates.berkeley.edu

\begin{abstract}
The editors of this special issue asked Todd LaPorte to reflect on the issues that emerge from the discussions in this special issue and, more in general, from the discussions that have proliferated in the wake of recent crises and disasters. In his contribution, Professor LaPorte contemplates what political leaders can do to prepare for catastrophic surprises. A crucial initiative, he argues, would be the initiation of a public discussion about the level of distress that a society is willing to accept in the pursuit of efficient, reliable critical infrastructures.
\end{abstract}

\section{Introduction}

$\mathrm{P}$ ublic policy consideration of 'critical infrastructure' (Cl) has exploded in the past dozen years; pressed on western audiences by the unhappy experiences of traumatic disasters visited upon the US, Europe and south Asia in the early 2000s. The litany is fearsome: the attack on New York City's twin towers, Hurricanes Katrina and Rita blasting through the Gulf Coast, the tsunami tidal wave in Indonesia, the bombings in Madrid and London. These events in the US and Europe have reinforced repeated rounds of posing unsettling questions about learning from these dramatic episodes. Indeed, the article by Boin and McConnell (this issue) cogently draws together many of the insights resulting from these disasters' grievous consequences.

One aspect of the policy and analytical hand-wringing has been devoted to a kind of expected failures reaction to these episodes (Burns and Thomas, 2006; Cooper and Block, 2006). Less often have analytical efforts tried to dig deeper into understanding the physical and social infrastructures of the regions themselves and inquire about the robustness of the institu- tional worlds immediately affected by extreme events (the articles in this special issue are exceptions). Framed as 'critical infrastructures' $(\mathrm{Cls})$, they should be considered in the unsettling context of institutions that have increasingly become vulnerable to social predation as well as to natural disasters. ${ }^{2}$ In this commentary, I will consider this changing context. My comments are clustered around three questions: about the challenges to first and second responders; about the lessons the institutional stewards of $\mathrm{Cl}$ have yet to learn; and about sustaining institutional commitments to worst-case preparation.

I. What are the institutional implications for civil society of the almost universally modest capacities of first and second responders who operate the public service infrastructures upon which social order depends?

Stark examples of vulnerabilities were revealed in the responses of US institutions to one of the most accurately estimated natural disasters in US history - 
the flooding of New Orleans by Hurricane Katrina and one of the most surprising acts of social predation in US history - the attack on New York City's Twin Towers. These are paralleled, of course, by the responses to the Asian Tsunami and to the bombings in Spain and London.

Some disasters - these certainly - become catastrophes. In the pointed language of Kathleen Tierney's (2006) work, 'they have extremely large physical and social impacts; large areas are affected, there are many deaths and injuries ..., and infrastructural damage are very severe and extensive' (Tierney, 2006). Such episodes call upon an array of first and second responders who, in the case of the catastrophes mentioned above, confronted demands well beyond their capacities when these surprises occurred. Each instance presented novel, unprecedented institutional operating conditions and analytical challenges. These experiences all produced effects that were well beyond imaging.

These and other recent 'extreme events' suggest that institutional leaders and analysts have some distance to go before the most salient lessons will have been learned and before confident recommendations can be put forward, especially considering the nation's $\mathrm{Cl}$. It is obvious that first and second responding institutional leaders and operating personnel at local, regional and national levels have repeatedly been taken aback by the intensity and extensiveness of these episodes. Katrina, especially, produced local elite panic (amplified by national media) even as the New Orleans area populations were hunkering down. ${ }^{3}$ The response to Hurricane Rita was more measured, though in all these cases, the depth and magnitudes of effects staggered the imagination.

First, I briefly note reasons that institutional surprises are likely, suggest the state of play on the ground now, and add to and reinforce some of the insights from other articles in this special issue. I turn then to some of lessons we have yet to learn - about planning and the preparing for communities responses to infrastructure catastrophes.

What conditions are likely to be major contributors to the depth of planning and operational surprises? Boin and McConnell (this issue) summarized many of them. Let me add several more that confound the usually tacit assumptions that inform planning and reduce operating beyond imagining. I list with limited comment four other sources of surprise. Together they account partially for insufficient responses on the ground and also for the truncated current organizational and institutional perspectives analysts are using to consider activities to buttress first and second responder capacities in 'managing $\mathrm{Cl}$ risk' and to facilitate recovering from the loss of infrastructure capacities in the face of extreme events. ${ }^{4}$
Increasingly dense, geographically dispersed and interdependent technical, economic, social infrastructure networks and communities

In consequence, technical and organizational networks become increasingly fragile with decreasing robustness even when they are well funded. In the face of current sustained efforts in realizing 'micro-efficiencies', organizational capacities are increasingly brittle with declining redundancy and very limited resilience. The result is an increasing likelihood of disruption and damaging effects where local capacities are overwhelmed. ${ }^{5}$

Limited local institutional capacities for providing foresights when these do become essential

There remain only modest analytical planning resources available to local and regional first and second responders. This greatly increases burdens upon local institutional leaders as they prepare for and attempt to motivate community action. This situation is likely to persist, in the face of highly constrained resources, and a perception that there is very low likelihood that any single urban community itself will experience extreme natural events and/or social predation.

Two other conditions, which have gained recognition in the post-9/1I period, substantially add to the potentials for surprise, distress and the burdens shouldered by first and second responders.

Increasingly destructive capacities are widely available at local and regional levels throughout a global distribution system

Examples in the use of a variety of moderately sized explosives and small arms play out across the Middle East, south Asia and northern and central Africa in remarkable abundance. Thus far, these capacities have yet to include chemical or very high explosive weapons.

The rise and maturity of widely dispersed adversaries who harbor deep, long-term hostility to Western cultural, economic and political institutions

These elements include significant numbers of people who do not share with us the assumption that physical survival is a key determinant of self interest. ${ }^{6}$ Together with available small and moderately sized weapons, both the means and apparently the will are increasing for adversaries to engage in potentially highly destructive social predation, some of which could thrust upon infrastructure nodes of vulnerability.

Considering the viability of $\mathrm{Cl}$ in the face of extreme conditions, we should ask ourselves what we have learned through experience, post $9 / 1 /$ and the traumas of the Indonesian tsunami and Hurricane Katrina? Here are four lessons.

- We can be badly surprised even in the most examined of situations; 
- Institutional capacities to deal with reasonably large-scale disasters can be overwhelmed within a reasonably short period of time;

- Both natural and deliberate disasters can result in such disruption of civil society and community that the processes of self-organized recombination of local resources often noted in responses to disasters of lesser magnitude cannot arise;

- The dislocation, loss of community and damage to civil society can be so deep and severe that recovery may occur only after quite long term, persistent efforts - if then.

\section{For the institutional stewards of $\mathrm{Cl}$, what lessons do we have yet to learn?}

Two challenges are inescapable. First, they should devise confident capacities to respond to those contingencies that can be imagined - i.e., planning for rare, but experienced events - across numerous political and operating generations. These are the events about which most commentators provide alerts and counsel (indeed, much of the Boin and McConnell article addresses important aspects of this challenge).

Second, they should develop 'at the ready' institutional capacities to encounter catastrophic surprises that could overwhelm conventional capabilities, and, in very rare instances, the essentials of local civil society itself. In the background of these points is the matter of institutional conditions that would be needed to assure the presence of sustainable response capacities even when the need to exercise them occurs only rarely.

This second challenge is of crucial importance. Leaders of $\mathrm{Cls}$ and community institutions must prepare 'to be very surprised' and to expect public institutions and patterns of civil society to be seriously weakened. Several pointers for leaders follow from this observation.

Institutional leaders and senior operating personnel should vigorously seek ways to get credible, systematic feedback about the extent and depth of injury as a result of an assault on $\mathrm{Cls}$ and the social organizations that animate them. While there has been some consideration of the technical demands of such reconnaissance and feedback capacities, ${ }^{7}$ fine tuning their specifics in terms of particular communities will, of course, be essential along with the means to recognize, measure and collect data that provides an alert to the onset of threats to the agreed upon conditions of suffering that should be avoided altogether, what Schulman termed, 'precluded conditions' ${ }^{8}$ One of the more unsettling lessons from Katrina was the sense that in extreme situations the region edged toward just such conditions, something like a community-wide experience of 'traumatic stress syndrome' (cf. Barton, 1970).
Preparation for this sort of surprise requires much more serious attention to maintaining therapeutic treatment to whole communities, including mental health capacities.

At the same time, leaders should take responsibility for assuring sustained debate within communities or regions that focus explicitly on what ought at minimum to be those conditions of suffering that should be avoided altogether already noted above. These provide the boundary or limiting conditions for designing infrastructure operating and preparation regimes. Combining a relatively clear agreement about those conditions or consequences that communities never wish to sacrifice along with the capacities that enable institutions to sense that they are threatened then allows for more effective, and earlier, warnings that surprises could occur.

Operational leaders, especially, could sort out those institutional norms and processes that, in calmer times, act to facilitate public functions (e.g., accountability practices) but become inhibitors to fashioning novel responses in times of crisis when flexibility and improvisation is in order. Retrospective analysis, sometimes in the 'lessons learned' phase of the crisis aftermath, affords such an opportunity. A key element would clearly be a sharp eye to establishing 'rules of exception' beforehand so that operational leaders responding to surprise do not sense they would be punished ex post for ignoring constraining norms. ${ }^{9}$

Finally, it is worth asking whether institutions can prepare to be surprised? What kinds of exercises would enhance infrastructure operators' capacities to embrace surprise-responding processes in organizational and community settings? This suggests repeated, high profile engagement of likely institutional leaders (along with keen public observers) in exercises where the whole organization is confronted with, say, a simulated extreme situation conducted over several days in which senior leadership would face situations well beyond their experience, along with the means to imagine various types of response, and careful debriefing of the collective result. The objective would be to give members of likely initial response teams a chance to discover their own propensities in the face of very unusual situations and increase their skills at working with novel combinations of institutional and community leaders. ${ }^{10}$

\section{How to assure sustained commitment to worst-case preparations?}

All of this so far is well and good. Much of it has already been noted in somewhat different terms in a variety of planning literatures. It also has the muted ring of utopian planning to it. One can hear the skeptics 
mutter, 'Oh, please, with the capacity for individual and elite denial of future distress, give me a break! You don't really suppose such processes would actually be put in place - and be SUSTAINED!'.

Indeed, given the demands of everyday operational and political life, preparing for horrific events that would cripple infrastructures seemingly in the distant future calls for extraordinary levels of leadership. What would leaders be called on to do - imperatives, so to say - to assure the degree and intensity of institutional commitments implied above? What is indicated if we are to take seriously a continuous demand to keep preparing - endlessly - for grievous surprise that rarely actually bedevils a single community?

Two activities at least seem absolutely necessary. They both address the deep seated tendency for leaders of economic and political institutions, along with those who speak for civic society more generally, to shrink from directly addressing measures that stem from potentially grievous consequences.

Institutional leaders have responsibilities to inspire citizen dread and to estimate the expected suffering facing communities and regions given their present institutional capabilities to ameliorate distress in the context of the ecological and infrastructure characteristics that exist. Such activities are, of course, most gingerly considered if at all by the institutions that hold the necessary information to execute them. My injunctions will seem 'beyond the pale' for public affairs officers and senior executives who have been burned by media and political scrutiny. Nonetheless, if institutions need to or are pressed to prepare for horrific surprises, something along these lines is necessary.

The foundation for such efforts would require, first, a relatively nuanced description of the 'best local institutions could do, given the hand they are dealt'. This means a clear accounting of the present capacities available to engage in infrastructure services when they are faced with a variety of demanding circumstances. These would include at least existing resources, manning levels, operational training and command and control experience. In addition, the social incentives for agreeing on 'precluded conditions or events' should be founded on clarity about the high costs of failure, and deep seated social fear. Indeed, the propensity to deny the potential for untoward future circumstances suggests that one of the crucial obligations of infrastructure leadership is the production of civic dread concerning the consequences of system failure. For example, one could imagine public institutions having within them Offices of Civic Dread Assurance. Without something like this function, the necessary resources and motivation will flag.

$\mathrm{Cl}$ functions undergird civic society and provide a kind of floor upon which social and community experience is encountered. And extensive infrastructural failures can result in extensive suffering. As the complex interdependent patterns of infrastructure grow, the need to maintain their robustness grows as well, often beyond the willingness of elites to pay for confident operations.

Thus, a final obligation falls on infrastructure leaders: to have the political courage to prepare communities to accept collective suffering. That is, to prepare communities for the unavoidable suffering associated with competitive, efficiency seeking society. One way to express this courage would be to insist on something like a widely published, bi-annual, community based Index of Expected Suffering (IES). Rooted in local knowledge, such an index would include estimates of the degrees of community vulnerability, judgments on the present robustness of institutional capacities, the grass roots capabilities for self-organization, and the various financial and policy mechanisms confidently available for healing, remediation, and longer term recovery. When these are matched with the sorts of damage, social dislocation, collapse of consistent public health services, and loss of civic society, one can estimate how much amelioration existing infrastructure could likely accommodate. That is, having a reasonably accurate, finely grained description of the extent, depth and severity of damage to existing infrastructure could inflict, as well as an expression of the present level of institutional capabilities to absorb this damage, one can being to estimate what suffering would go unattended.

What is left unaddressed after each type of emergency or predatory attack, after all presently available resources have been deployed, are the grounds for estimating the social and individual suffering of citizens left adrift. Periodic reminders of this likely suffering provide a kind of stewardship benchmark against which to consider expressions of policy satisfaction or increased obligations. Without something like these efforts, pronouncements about the importance of assuring institutional capacities to secure society's $\mathrm{Cl}$ remain nearly banal and merely nourish public skepticism.

\section{Acknowledgements}

This paper was presented to the workshop on 'Protecting Critical Infrastructures: Vulnerable Systems, Modern Crises, and Institutional Design', Conference on Future Challenges for Crisis Management in Europe, Stockholm, 4-5 May 2006. It draws in part from comments offered in 'Preparing for untoward surprise: Lessons yet to be learned - Post Katrina and Post 9/I I', National Symposium on Risk and Disasters: Lessons from Hurricane Katrina for American Life, Rebuilding the Gulf, Washington, D.C., Dec. 2005; and Berkeley Symposium on Real Estate, Catastrophe, Risk and 
Public Policy' Berkeley Program on Housing and Urban Policy, Haas School of Business, UCB (March 23, 2006).

\section{Notes}

I. See also Daniels, Kettl and Kunreuther (2006) and Farber and Chen (2006).

2. It is instructive to note the wide range of systems that have been put forward to inhabit this category. See especially the 'critical infrastructure' entry in the Wikipedia open source listing. It is an indication of what one might call the views of the attentive public.

3. See evidence of this and other symptoms of institutional incoherence scattered across a number of recently published accounts and reviews, e.g., Cooper and Block (2006) op cit.; Brinkley (2006); Horne (2006); McQuaid and Schleifstein (2006); Tidwell (2006).

4. For a daunting overview of the institutional challenges that derive from catastrophic infrastructure failures see Boin et al. (2005).

5. See especially the collected papers in Auerswald et al. (2006).

6. LaPorte (2006) op cit.

7. See especially Comfort's work, for example, Comfort (1999; 2006) and Comfort et al. (200I).

8. See especially Schulman's discussion of establishing a menu of 'precluded events/conditions' in the development of response capabilities (Schulman, 2004), www.qshc.com.

9. An important concern in allowing policies of exceptions or waivers is rightly the worry of many institutional leaders that these policies could result in losses in the legitimate functionality of classical processes in times of normality. Means confidently to incorporate both types of processes, with clear markers for when exceptions are warranted, is one of the most pressing analytical challenges before those likely to read this issue.

10. There are some computer simulation/game playing programs, of course. One senses they have limited value in situations like this. Perhaps the closest thing to this type of activity that exists in the US is the FEMA stipulated, biennial exercises for each nuclear utility to demonstrate 'the adequacy of the radiological emergency preparedness and response plans'. These exercises assemble all the institutional and community decision-maker who would in an actual emergency be called on to work together.

\section{References}

Auerswald, P., Branscomb, L.M., LaPorte, T.M. and MichelKerjan, E. (Eds) (2006), Seeds of Disaster, Roots of Response: How Private Action Can Reduce Public Vulnerability, Cambridge University Press, Cambridge.
Barton, A.H. (1970), Communities in Disaster: A Sociological Analysis of Collective Stress Situations, Doubleday, Garden City, NJ.

Boin, R.A., 't Hart, P., Stern, E. and Sundelius, B. (2005), The Politics of Crisis Management: Public Leadership under Pressure, Cambridge University Press, Cambridge.

Boin, R.A. and McConnell (2007), 'Preparing for Critical Infrastructure Breakdowns: The Limits of Crisis Management and the Need for Resilience', Journal of Contingencies and Crisis Management, Volume 15, Number I, PP. 50-59.

Brinkley, D.G. (2006), The Great Deluge: Hurricane Katrina, New Orleans and the Mississippi Gulf Coast, William Morrow, New York.

Burns, P. and Thomas, M.O. (2006), 'The Failure of the Nonregime: How Katrina Exposed New Orleans as a Regimeless City', Urban Affairs Review, Volume 4I, Number 4, pp. 5I7-527.

Comfort, L.K. (1999), Shared Risk: Complex Systems in Seismic Response, Pergamon Press, New York.

Comfort, L.K. (2006), 'Cities at Risk: Hurricane Katrina and the Drowning of New Orleans', Urban Affairs Review, Volume 4I, Number 4, pp. 50I-5I6.

Comfort, L.K., Sungu, Y., Dunn, M. and Johnson, D. (200I), 'Complex Systems in Crisis: Anticipation and Resilience in Dynamic Environments', Journal of Contingencies and Crisis Management, Volume 9, Number 3, pp. 144-158.

Cooper, C. and Block, R. (2006), Disaster: Hurricane Katrina and the Failure of Homeland Security, Times Books, New York.

Daniels, R.J., Kettl, D.F. and Kunreuther, H. (Eds) (2006), On Risk and Disaster: Lessons from Hurricane Katrina, University of Pennsylvania Press, Philadelphia, PA.

Farber, D.A. and Chen, J. (Eds) (2006), Disasters and the Law: Katrina and Beyond, Aspen Publishers, New York.

Horne, J. (2006), Breach of Faith: Hurricane Katrina and the Near Death of a Great American City, Random House, New York.

LaPorte, T.R. (2006), 'Challenges of Assuring High Reliability When Facing Suicide Terrorism', in Auerswald, P., Branscomb, L.M., LaPorte, T.M. and Michel-Kerjan, E. (Eds), Seeds of Disaster, Roots of Response: How Private Action Can Reduce Public Vulnerability, Cambridge University Press, Cambridge, Pp. 99-121.

McQuaid, J. and Schleifstein, M. (2006), Path of Destruction: The Devastation of New Orleans and the Coming Age of Superstorms, Little, Brown, London.

Schulman, P.R. (2004), 'General Attributes of Safe Organizations', Quality and Safety in Health Care, Volume 13, Number 2, pp. ii39-ii44.

Tidwell, M. (2006), The Ravaging Tide: Strange Weather, Future Katrinas, and the Coming Death of America's Coastal Cities, Free Press, Northampton.

Tierney, K. (2006), 'Hurricane Katrina: Catastrophic Impact and Alarming Lessons', Berkeley Symposium on Real Estate, Catastrophe, Risk and Public Policy, Berkeley Program on Housing and Urban Policy, Haas School of Business, University of California Berkeley, March 23. 